\title{
Factor Substitution and Employment
}

\author{
Hideki Nakamura \\ Faculty of Economics, Osaka City University, Osaka, Japan \\ Email: hnakamur@econ.osaka-cu.ac.jp
}

How to cite this paper: Nakamura, H. (2018) Factor Substitution and Employment. Modern Economy, 9, 1127-1136. https://doi.org/10.4236/me.2018.97074

Received: May 4, 2018

Accepted: June 26, 2018

Published: June 29, 2018

Copyright $\odot 2018$ by author and Scientific Research Publishing Inc. This work is licensed under the Creative Commons Attribution International License (CC BY 4.0).

http://creativecommons.org/licenses/by/4.0/

\begin{abstract}
This paper explores how employment among an educated workforce depends on production technology represented by factor substitution and factor-augmenting technical progress. We consider a variant of the Diamond overlapping generations model that can explain the empirical finding about the elasticity of substitution being less than unity observed in some developed economies. Depending on factor substitution, a decline in the wage rate has positive and negative effects on employment. When the elasticity of substitution is less than unity, a low wage rate can imply a low employment rate as well as a low human capital level. Given the elasticity of substitution, being less than unity, labor-augmenting technical progress can decrease the employment rate and human capital level via a decrease in the marginal product of labor.
\end{abstract}

\section{Keywords}

Factor Substitution between Capital and Labor, Factor-Augmenting

Technical Progress, Employment Among an Educated Workforce, Wage

Rigidity, Diamond Overlapping Generations Model

\section{Introduction}

While the aggregate production function plays an important role in economic growth theories, many studies assume a Cobb-Douglas production function because of its tractability. However, some studies found little evidence in some developed economies to support the assumption of a Cobb-Douglas production function (see [1] [2] [3] [4]).

This study examines how production technology represented by factor substitution and factor-augmenting technical progress affects the economic development of a country which cannot attain full employment of educated workers. Our model has two important features. The first feature is a constant elasticity of 
substitution (CES) production function in a variant of the [5] overlapping-generations model. While in a dynasty model, individual savings come out of total income, it implies relatively high economic growth with a higher elasticity of substitution. However, it may not be able to explain the empirical finding that the elasticity of substitution between capital and (skilled) labor lies below unity in developed economies. Thus, we employ a CES production function in a model in which individual savings come out of wage income. The second feature is downward rigidity in the wage rate. Given the wage rigidity, we can examine the dynamics of employment rate and human capital level.

In our model, a decline in the wage rate has not only a positive effect, but also a negative effect on the employment rate. Because the decline in the wage rate decreases the threshold in the capital/labor ratio for attaining full employment, it increases the employment rate. However, the decline in the wage rate implies a low income level. It decreases the employment rate because of a low capital/labor ratio. Thus, the total effect of wages on employment depends on factor substitution. When the elasticity of substitution lies below unity, a low wage rate can imply a low employment rate as well as a low human capital level because the negative effect can outweigh the positive effect.

Given the elasticity of substitution, being less than unity, labor-augmenting technical progress can decrease the employment rate and human capital level via a decrease in the marginal product of labor because the marginal product of capital increases more rapidly than output per capita. Factor substitution itself has an ambiguous effect on the employment rate and human capital level.

To begin, we posit the following. [8] showed that in the Diamond model, low growth can be implied by a relatively high elasticity of substitution. This paper tries to examine the effect of production technology on employment among an educated workforce because in many developed economies, prolonged economic stagnation has been observed and educated individuals do not always work as skilled workers. We show that under complementary relationships between capital and labor, both the employment rate and the human capital level can be low with a low wage rate or with labor-augmenting technical progress. ${ }^{2}$

The remainder of this paper is organized as follows. In Section 2, we explain our model. In Section 3, we investigate the employment and education associated with factor substitution. We conclude the paper in Section 4.

\section{Model}

Assume that individuals live for three periods. In the first period, individuals receive education. In the second period, individuals work. During this period, they decide their own consumption and savings as well as their children's level of ${ }^{1}$ For simplicity, we consider the employment rate which is an average of the employed and unemployed workers. In the Appendix, we provide a microfoundation of wage rigidity using the efficiency wage hypothesis (see [6] [7]).

${ }^{2}[9]$ examined the divergence of unemployment rates between the United States and Europe. He explained the divergence of unemployment rates across economies by technology adoption, and not by unemployment insurance. 
education. In the third period, individuals consume their own income.

We describe the formation of human capital. Whereas educational investment increases the human capital stock, the returns on education are diminishing:

$$
h_{t}=\left(o+e_{t}\right)^{\gamma},
$$

where $0<o$ and $0<\gamma<1 . h_{t}$ is the human capital stock, and $e_{t}$ is the educational level. We assume the positive amount of human capital stock represented by $o$.

We consider the utility maximization problem of an individual born in period $t-1$. We assume that parental preferences depend on consumption in periods $t$ and $t+1$ and the potential income level, that is, the human capital level, of their children. Parents use their income for consumption in period $t$, for educational expenditure on their children, and for savings. The utility maximization problem of an individual born in period $t-1$ is as follows:

$$
\begin{gathered}
\max _{c_{y t}, e_{t}, s_{t}} u_{t} \equiv c_{y t}^{\beta_{y}}\left(w h_{t+1}\right)^{\beta_{h}} c_{o t+1}^{\beta_{o}}, \\
\text { s.t. } w x_{t} h_{t}=c_{y t}+w e_{t}+s_{t}, \\
c_{o t+1}=r s_{t},
\end{gathered}
$$

where $0<\beta_{y}<1,0<\beta_{h}<1,0<\beta_{o}<1$, and $0<\phi$. For simplicity, we assume that $\beta_{y}+\gamma \beta_{h}+\beta_{o}=1 . W$ is the wage rate and $r$ is the gross interest rate. $c_{y t}$ and $c_{o t+1}$ are the consumption levels of the second and third periods, respectively, $s_{t}$ is the savings, and $x_{t}$ is the employment rate with $0<x_{t} \leq 1$. We assume the cost of education is proportionate to the wage rate.

The first-order conditions of the utility maximization problem are as follows:

$$
\begin{gathered}
c_{y t}=\beta_{y} w\left(x_{t} h_{t}+o\right), \\
s_{t}=\beta_{o} w\left(x_{t} h_{t}+o\right), \\
e_{t}=\beta_{h} \gamma x_{t} h_{t}-\left(\beta_{y}+\beta_{o}\right) o .
\end{gathered}
$$

Educational expenditure with respect to income is convex because of the constant term in the human capital stock. We assume a positive amount of educational investment in the initial period:

$$
\beta_{h} \gamma x_{0} h_{0}>\left(\beta_{y}+\beta_{o}\right) o \text {. }
$$

From (1) and (7), the dynamics of human capital are represented as follows:

$$
h_{t+1}=\left(\beta_{h} \gamma\right)^{\gamma}\left(x_{t} h_{t}+o\right)^{\gamma} .
$$

The existence of unemployment retards the accumulation of human capital.

Next, we consider perfectly competitive firms. We assume a CES production function:

$$
Y_{t}=\left[b K_{t}^{-\rho}+(1-b)\left(h_{t} N_{t}\right)^{-\rho}\right]^{-1 / \rho} \equiv f\left(k_{t}\right) h_{t} N_{t},
$$

where $0<b<1,-1<\rho<\infty$, and $k_{t} \equiv \frac{K_{t}}{h_{t} N_{t}} . N_{t}$ is the number of employed 
workers. The elasticity of substitution between capital and labor is $\sigma \equiv \frac{1}{1+\rho}$.

We assume downward rigidity in the wage rate. Given the factor prices, the first-order conditions are as follows:

$$
\begin{gathered}
w=f(k)-f^{\prime}(k) k \equiv G(k), \\
r=f^{\prime}(k) .
\end{gathered}
$$

\section{How Does Production Technology Affect Employment and Education?}

We assume that in the initial period, the marginal product of labor is less than the wage rate:

$$
G\left(k_{0}\right)<w,
$$

where $k_{0}=\frac{K_{0}}{h_{0} P} . P$ is the population size of each generation.

The threshold in the capital/labor ratio for attaining full employment can be represented by $k$. We obtain:

$$
k=G^{-1}(w)=b^{1 / \rho}\left[\left(\frac{w}{1-b}\right)^{-\rho /(1+\rho)}-(1-b)\right]^{-1 / \rho} \equiv k(w) .
$$

where $k^{\prime}(w)>0$. That is, an increase in the wage rate increases the threshold for attaining full employment.

Savings in period $t$ form the physical capital in period $t+1$ as follows:

$$
K_{t+1}=s_{t} P=\beta_{o} w\left(x_{t} h_{t}+o\right) P .
$$

From this, we have:

$$
\frac{K_{t+1}}{h_{t+1} N_{t+1}} \frac{h_{t+1} N_{t+1}}{P}=k(w) x_{t+1} h_{t+1}
$$

Note that $x_{t+1}=\frac{N_{t+1}}{P}$.

While the income level in period $t$ is proportionate to $x_{t} h_{t}$, the dynamics in $x_{t} h_{t}$ are represented as follows:

$$
x_{t+1} h_{t+1}=\frac{\beta_{o} w}{k(w)}\left(x_{t} h_{t}+o\right) .
$$

Equation (13) shows the negative and positive effects of a decline in the wage rate on the income level when individuals are not fully employed. On the one hand, the numerator of (13) represents the negative effect of the declining wage rate on the income level because savings depend on wage incomes. The denominator of (13), on the other hand, represents the positive effect of the declining wage rate on the income level via the threshold in the capital/labor ratio for attaining full employment.

We consider the existence of a stable steady state of the economy in which unemployment exists: 


$$
\frac{\beta_{o} w}{k(w)}<1 \text { and } x<1
$$

We see the dynamics of the human capital level and employment rate from (8) and (13). As shown in Figure 1, the dynamics of the income level are autonomous. Given the initial level, $x_{0} h_{0}$, the income level increases with $x_{t} h_{t}$ and converges to $w x h$. Under Assumption (A3), the human capital level and employment rate at the steady state are respectively represented as follows:

$$
\begin{gathered}
h=\left(\beta_{h} \gamma\right)^{\gamma}\left[\frac{\frac{\beta_{o} w}{k(w)} o}{1-\frac{\beta_{o} w}{k(w)}}+o\right]^{\gamma}, \\
x=\frac{\frac{\beta_{o} w}{k(w)} o}{1-\frac{\beta_{o} w}{k(w)}}\left(\beta_{h} \gamma\right)^{-\gamma}\left[\frac{\frac{\beta_{o} w}{k(w)} o}{1-\frac{\beta_{o} w}{k(w)}}+o\right]^{-\gamma} .
\end{gathered}
$$

We use the normalization procedure to examine unemployment with factor substitution. We arbitrarily choose baseline values for three variables: the capital/labor ratio, $\bar{k}$; the output/labor ratio, $\bar{y}$; and the marginal rate of substitution, $\bar{m} \equiv \frac{\partial Y_{t}}{\partial K_{t}} / \frac{\partial Y_{t}}{\partial h_{t} N_{t}}$, which are evaluated at $\bar{k}$ (see [10]). The normalized CES production function is:

$$
Y_{t}=C(\sigma)\left[b(\sigma) K_{t}^{-\rho}+(1-b(\sigma))\left(h_{t} N_{t}\right)^{-\rho}\right]^{-1 / \rho}
$$

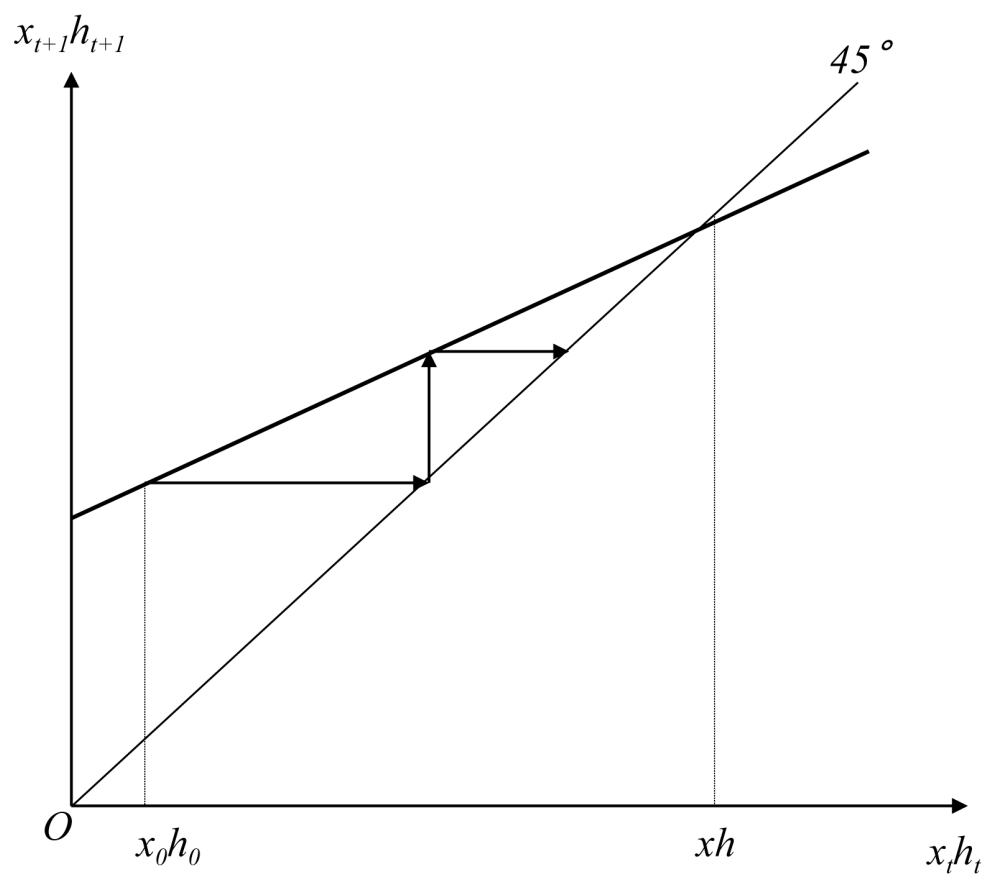

Figure 1. Dynamics of income level when individuals are not fully employed. 
where $b(\sigma) \equiv \frac{\bar{k}^{1+\rho}}{\bar{k}^{1+\rho}+\bar{m}}$ and $C(\sigma) \equiv \bar{y}\left(\frac{\bar{k}^{1+\rho}+\bar{m}}{\bar{k}+\bar{m}}\right)^{-1 / \rho}$.

We now examine the effects of wage and factor substitution on the employment rate and human capital level.

Lemma 1: (Comparative statics). Suppose Assumptions (A1)-(A3) hold. 1) We have $\frac{\partial h}{\partial w} \geq 0, \frac{\partial x}{\partial w} \geq 0$, and $\frac{\partial x h}{\partial w} \geq 0$ when

$$
\left(\frac{1-b(\sigma)}{w}\right)^{1-\sigma}(1-\sigma) \frac{\geq}{<} 1-b(\sigma) .
$$

2) When $\frac{\sigma-1}{\sigma}>\frac{\bar{m}}{\bar{k}}$, we obtain $\frac{\partial h}{\partial \sigma}<0, \frac{\partial x}{\partial \sigma}<0$, and $\frac{\partial x h}{\partial \sigma}<0 \quad(k>\bar{k})$.

Proof: 1) From (14) and (15), $\frac{\partial h}{\partial w}, \frac{\partial x}{\partial w}$, and $\frac{\partial x h}{\partial w}$ depend positively on $\frac{w}{k(w)} \cdot \frac{\mathrm{d} \frac{w}{k(w)}}{\mathrm{d} w} \frac{<}{<}$ can be represented as:

$$
\left(\frac{w}{1-b(\sigma)}\right)^{-(1-\sigma)}(1-\sigma) \underset{<}{\geq} 1-b(\sigma) .
$$

Note that $1-\sigma=\frac{\rho}{1+\rho}$.

2) The differentiation of the marginal product of labor with respect to the elasticity of substitution is as follows:

$$
\left.\frac{\partial G(k: \sigma)}{\partial \sigma}\right|_{\text {given } k}+\frac{\partial G(k: \sigma)}{\partial k} \frac{\partial k}{\partial \sigma}=0
$$

When $-\rho>\frac{\bar{m}}{\bar{k}}$, that is, when $\frac{\sigma-1}{\sigma}>\frac{\bar{m}}{\bar{k}}$, we have $\left.\frac{\partial G(k: \sigma)}{\partial \sigma}\right|_{\text {given } k}<0$ for any $k>\bar{k} \cdot{ }^{3}$ Furthermore, we have $\frac{\partial G(k: \sigma)}{\partial k}>0$. Thus, from (18), given that $\frac{\sigma-1}{\sigma}>\frac{\bar{m}}{\bar{k}}$, we have $\frac{\partial k}{\partial \sigma}>0$, which implies $\frac{\partial h}{\partial \sigma}<0, \frac{\partial x}{\partial \sigma}<0$, and $\frac{\partial x h}{\partial \sigma}<0 . \|$

The threshold of the capital/labor ratio for attaining full employment depends positively on the wage rate. Thus, a decline in the wage rate can increase the employment rate and human capital level because of a decrease in the threshold. However, the decline in the wage rate decreases savings. It can decrease the employment rate and human capital level because of a low level of capital accumulation. When $\sigma \geq 1$, the positive effect always outweighs the negative effect because the marginal product of labor increases slowly with capital accumulation. Thus, a low wage rate can improve the employment rate and human capital level. However, under the complementary relationship between capital and labor $(\sigma<1)$, the negative effect can outweigh the positive effect because of a large ${ }^{3}$ This part of the proof is the same as that of [8] [11]. 
marginal product of labor. Thus, a low wage rate does not necessarily imply an improvement in the employment rate and human capital level.

Additionally, a rise in education quality can decrease the employment rate but raise the human capital level. This implies the trade-off between the human capital level and the employment rate.

We also examine the effect of factor substitution itself on the employment rate and human capital level. Although a high elasticity of substitution between capital and labor can potentially imply a high output/labor ratio, the marginal product of labor increases less rapidly. Thus, when capital and labor are relatively substitutable, an increase in the elasticity of substitution decreases the employment rate and human capital level because of a decrease in the marginal product of labor.

Proposition 1: (Effect of wage and factor substitution on unemployment). Suppose Assumptions (A1)-(A3) hold. If the elasticity of substitution between capital and labor lies below unity, the unemployment problem cannot be necessarily solved by a low wage rate because of the existence of both positive and negative effects. Furthermore, the elasticity of substitution itself has an ambiguous effect on the employment rate and human capital level.

Finally, we consider the effect of factor-augmenting technical progress:

$$
Y_{t}=\left[b(\sigma)\left(\theta_{K} K_{t}\right)^{-\rho}+(1-b(\sigma))\left(\lambda_{L} h_{t} N_{t}\right)^{-\rho}\right]^{-1 / \rho},
$$

where $\theta_{K}>0$ and $\lambda_{L}>0$. Increases in $\theta_{K}$ and $\lambda_{L}$ represent capital-augmenting progress and labor-augmenting technical progress, respectively.

Proposition 2: (Effect of factor-augmenting technical progress on employment). Suppose Assumptions (A1)-(A3) hold. Capital-augmenting technical progress always increase the employment rate and human capital level. However, if the elasticity of substitution between capital and labor lies below unity, labor-augmenting technical progress can decrease the employment rate and human capital level because of a decrease in the marginal product of labor.

Proof: We obtain $\frac{\partial k}{\partial \theta_{K}}<0$ from $\frac{\partial G(k)}{\partial \theta_{K}}>0$. Thus, we have $\frac{\partial h}{\partial \theta_{K}}>0$, $\frac{\partial x}{\partial \theta_{K}}>0$, and $\frac{\partial x h}{\partial \theta_{K}}>0$. Furthermore, we always have $\frac{\partial G(k)}{\partial \lambda_{L}}>0$ where $\sigma \geq 1$. However, when the following inequality holds with $\rho>0$, that is, with $\sigma<1$,

$$
(1-b(\sigma)) \lambda_{L}^{-\rho}<\rho b(\sigma)\left(\theta_{K} k\right)^{-\rho},
$$

we obtain $\frac{\partial k}{\partial \lambda_{L}}>0$ from $\frac{\partial G(k)}{\partial \lambda_{L}}<0$. That is, we have $\frac{\partial h}{\partial \lambda_{L}}<0, \frac{\partial x}{\partial \lambda_{L}}<0$, and $\frac{\partial x h}{\partial \lambda_{L}}<0$ with condition (20). ॥

Capital-augmenting technical progress always decreases the threshold of the capital/labor ratio for attaining full employment because of an increase in the 
marginal product of labor. However, the effect of labor-augmenting technical progress depends on factor substitution. When capital and labor are complements, labor-augmenting technical progress can decrease the marginal product of labor because the marginal product of capital increases more rapidly than the output/labor ratio. Thus, the employment rate and human capital level can decrease because of labor-augmenting technical progress.

\section{Concluding Remarks}

This study explored how factor substitution and factor-augmenting technical progress affect employment among educated workers because of little evidence to support the assumption of a Cobb-Douglas production function. We found that a low wage rate can imply a low employment rate as well as a low human capital level when the elasticity of substitution lies below unity. Given the elasticity of substitution, being less than unity, labor-augmenting technical progress can decrease the employment rate and human capital level via a decrease in the marginal product of labor.

We can obtain some policy implications about employment and education. The government should be reminded that under complementary relationships between capital and labor, a decline in the wage rate or labor-augmenting technical progress can decrease both the employment rate and the human capital level. Furthermore, the government should not improve only the educational level when there are unemployed educated individuals. It could worsen the unemployment problem because of the trade-off between the human capital level and the employment rate.

\section{Acknowledgements}

I thank Masakatsu Nakamura and Hyunho Kim for their valuable comments. I also thank Duksup Shim and Lee Su-Yol for the courtesy extended during a symposium at the Chonnam National University.

\section{References}

[1] Krusell, P., Ohanian, L.E., Ríos-Rull, H.-V. and Violante, G.L. (2000) Capital-Skill Complementarity and Inequality: A Macroeconomic Analysis. Econometrica, 68 1029-1053. https://doi.org/10.1111/1468-0262.00150

[2] Chirinko, R.S. (2008) $\sigma$. The Long and Short of It. Journal of Macroeconomics, 30, 671-686. https://doi.org/10.1016/j.jmacro.2007.10.010

[3] León-Ledesma, M.A., McAdam, P. and Willman, A. (2010) Identifying the Elasticity of Substitution with Biased Technical Change. American Economic Review, 100, 1330-1357. https://doi.org/10.1257/aer.100.4.1330

[4] Klump, R., McAdam, P. and Willman, A. (2012) The Normalized CES Production Function: Theory and Empirics. Journal of Economic Surveys, 26, 769-779. https://doi.org/10.1111/j.1467-6419.2012.00730.x

[5] Diamond, P.A. (1965) National Debt in a Neoclassical Growth Model. American Economic Review, 55, 1126-1150. 
[6] Shapiro, C. and Stiglitz, J. (1984) Equilibrium Unemployment as a Worker Discipline Device. American Economic Review, 74, 433-444.

[7] Nakajima, T. (2010) A Simple Model of Keynesian Unemployment. Metroeconomica, 61, 239-256. https://doi.org/10.1111/j.1467-999X.2009.04055.X

[8] Miyagiwa, K. and Papageorgiou, C. (2003) Elasticity of Substitution and Growth: Normalized CES in the Diamond Model. Journal of Economics Theory, 21, 155-165. https://doi.org/10.1007/s00199-002-0268-9

[9] Duernecker, G. (2014) Technology Adoption, Turbulence, and the Dynamics of Unemployment. Journal of the European Economic Association, 12, 724-754. https://doi.org/10.1111/jeea.12041

[10] Klump, R. and de La Grandville, O. (2000) Economic Growth and Elasticity of Substitution: Two Theorems and Some Suggestions. American Economic Review, 90, 282-291. https://doi.org/10.1257/aer.90.1.282

[11] Nakamura, H. and Seoka, Y. (2014) Differential Fertility and Economic Development. Macroeconomic Dynamics, 18, 1048-1068.

https://doi.org/10.1017/S1365100512000818 


\section{Appendix}

This appendix provides a microfoundation of wage rigidity using the efficiency wage hypothesis. We rewrite the utility maximization problem as follows:

$$
\max _{c_{y t}, e_{t}, s_{t}, \xi_{t}} u_{t} \equiv c_{y t}^{\beta_{y}}\left(w h_{t+1}\right)^{\beta_{h}} c_{o t+1}^{\beta_{o}}-\xi_{t} \phi x_{t} h_{t},
$$

where $0<\phi . \xi_{t}$ is the efficiency at work. For simplicity, $\xi_{t}$ is assumed to equal zero or unity. $\xi_{t}=1$ and $\xi_{t}=0$ imply working hard and shirking, respectively.

If individuals work hard, they obtain labor income, denoted by $w x_{t} h_{t}$. If they shirk, the probability of detection is exogenously given by $q(0<q<1)$. Thus, under shirking, workers can obtain labor income with the probability of $1-q$ and can be dismissed with the probability of $q$. We assume that even when workers are dismissed, they can take up unskilled jobs in which the income level of unskilled labor is $v w x_{t} h_{t} \quad(0<v<1)$.

The decision with regard to efficiency at work can be examined separately from the choice of consumption and savings levels and of the education of children because we consider disutility in the additive form. We specify the utility level with efficiency at work as follows:

$$
u_{t}=B w\left(x_{t} h_{t}+o\right)-\xi_{t} \phi x_{t} h_{t},
$$

where $B \equiv \beta_{y}^{\beta_{y}}\left(\beta_{h} \gamma\right)^{\beta_{h} \gamma}\left(\beta_{o} r\right)^{\beta_{o}}$.

We examine the condition for working hard. The utility level under no shirking is represented as follows:

$$
\left.u_{t}\right|_{\xi_{t}=1}=B w\left(x_{t} h_{t}+o\right)-\phi x_{t} h_{t} .
$$

The expected utility under shirking, on the other hand, can be represented as:

$$
\left.(1-q) u_{t}\right|_{\xi_{t}=0, n d}+\left.q u_{t}\right|_{\xi_{t}=0, d}=(1-q) B w\left(x_{t} h_{t}+o\right)+q B w\left(v x_{t} h_{t}+o\right),
$$

where $\left.u_{t}\right|_{\xi_{t}=0, n d}$ and $\left.u_{t}\right|_{\xi_{t}=0, d}$ are the utility levels with no dismissal and dismissal, respectively.

Thus, (B3) and (B4) imply the following condition for working hard:

$$
\left.u_{t}\right|_{\xi_{t}=1}-\left[\left.(1-q) u_{t}\right|_{\xi_{t}=0, n d}+\left.q u_{t}\right|_{\xi_{t}=0, d}\right] \geq 0 .
$$

The threshold for efficiency wage is represented as:

$$
w=\frac{\phi}{B q(1-v)} .
$$

If the wage rate is sufficiently high to satisfy the threshold in (B5), individuals will not shirk, because they can obtain a higher utility level. Any rise in disutility under no shirking or decline in the probability of detection increases the threshold. A rise in unskilled labor income increases the threshold. 